\title{
Cardiovascular risk assessment in osteoporotic patients using osteoprotegerin as a reliable predictive biochemical marker
}

\author{
CARMEN G. BARBU ${ }^{1 *}$, ANDREEA L. ARSENE ${ }^{2}$, SUZANA FLOREA $^{1}$, ALICE ALBU $^{1}$, ANCA SIRBU $^{1}$, \\ SORINA MARTIN ${ }^{1}$, ALINA C. NICOLAE ${ }^{3}$, GEORGE T.A. BURCEA-DRAGOMIROIU ${ }^{4 *}$, DANIELA E. POPA ${ }^{4}$, \\ BRUNO S. VELESCU ${ }^{5 *}$, ION B. DUMITRESCU ${ }^{6}$, NICULINA MITREA ${ }^{3}$, DOINA DRAGANESCU ${ }^{6}$, \\ DUMITRU LUPULIASA ${ }^{7}$, DEMETRIOS A. SPANDIDOS ${ }^{8}$, ARISTIDES M. TSATSAKIS $^{9}$, \\ CRISTINA M. DRAGOI ${ }^{3}$ and SIMONA FICA ${ }^{2}$
}

\begin{abstract}
${ }^{1}$ Elias Hospital, Department of Endocrinology, Faculty of Medicine, 'Carol Davila'University of Medicine and Pharmacy, 011461 Bucharest; Departments of ${ }^{2}$ General and Pharmaceutical Microbiology, ${ }^{3}$ Biochemistry, ${ }^{4}$ Drug Control, ${ }^{5}$ Pharmacology and Clinical Pharmacy, ${ }^{6}$ Pharmaceutical Physics and Informatics, and ${ }^{7}$ Pharmaceutical Technology and Biopharmaceutics, Faculty of Pharmacy, 'Carol Davila' University of Medicine and Pharmacy, 020956 Bucharest, Romania;

${ }^{8}$ Laboratory of Clinical Virology, ${ }^{9}$ Laboratory of Toxicology, Medical School,

University of Crete, Heraklion 71003, Crete, Greece
\end{abstract}

Received April 10, 2017; Accepted August 8, 2017

DOI: $10.3892 / \mathrm{mmr} .2017 .7376$

\begin{abstract}
Osteoprotegerin (OPG), a member of the tumour necrosis factor receptor (TNFR) superfamily of proteins known to be involved in a large number of biological systems, plays a pivotal role in bone remodelling. In addition to the roles of OPG in bone metabolism, it has been reported to be associated with a high cardiovascular risk in patients with metabolic syndrome. In most cases, the exact functions of OPG remain to be established; however, the widespread expression of OPG suggests that this molecule may have multiple biological activities, mainly in the cardiometabolic environment. The aim of this study was to evaluate the value of OPG as a predictive marker for cardiovascular and metabolic risk in osteoporotic patients. The study group comprised patients with osteoporosis, in order to evaluate the association between OPG serum levels and cardiovascular pathology. Our results revealed significant correlations between classical biochemical bone and metabolic parameters, such as osteocalcin and parathyroid hormone with lipid and glucose
\end{abstract}

Correspondence to: Dr Andreea Letitia Arsene, Department of General and Pharmaceutical Microbiology, Faculty of Pharmacy, 'Carol Davila' University of Medicine and Pharmacy, 6th Traian Vuia, 020956 Bucharest, Romania

E-mail: andreeanitulescu@hotmail.com

Dr Alina Crenguta Nicolae, Department of Biochemistry, Faculty of Pharmacy, 'Carol Davila' University of Medicine and Pharmacy, 6th Traian Vuia, 020956 Bucharest, Romania

E-mail: alinanicolae29@gmail.com

*Contributed equally

Key words: osteoprotegerin, osteoporosis, metabolic syndrome, cardiovascular risk biomarkers, sustaining the crosstalk between calcium and bone parameters and cardiovascular risk. The OPG serum level proved to have a significant and independent predictive value for metabolic syndrome (MetS) as a cardiovascular risk standard in osteoporotic patients. The OPG serum levels were increased in patients with MetS as a protective response against the atherosclerotic lesions. The serum levels of 25-hydroxy vitamin D had significant and independent predictive value for cardiovascular and metabolic risk in our subjects, sustaining the active role of vitamin $\mathrm{D}$ beyond the area of bone metabolism.

\section{Introduction}

Metabolic syndrome (MetS) represents a cluster of cardiovascular and metabolic injuries that include mainly the presence of arterial hypertension, hyperglycaemia, insulin resistance, dyslipidaemia and obesity $(1,2)$. Currenlty, there is much concern regarding this pathology, as its incidence has markedly increased over the past 10 years, worldwide. There is increasing evidence to indicate that mortality due to cardiovascular events, including stroke, different cardiovascular diseases and myocardial infarction is highly influenced by the presence of metabolic imbalances $(3,4)$. Data from animal models, as well as from clinical studies have shown the strong association between diet, chronic exposure to xenobiotics and pesticides, and the high levels of oxidative stress and the emergence of MetS (5-10). Extensive research is currently being conducted in order to assess all the possible mechanisms underlying the etiopathogenesis of MetS.

Osteoprotegerin (OPG) has recently been highlighted as a key factor of the biochemical mechanisms underlying the association between MetS and cardiovascular risk (2,11-16). OPG is a soluble glycoprotein of the tumour necrosis factor receptor (TNFR) superfamily implicated in bone remodelling. It functions as a decoy receptor of receptor activator 
for nuclear factor $\kappa \mathrm{B}$ ligand (RANKL) and TNF-related apoptosis-inducing ligand (TRAIL). For its particular ability to block RANKL, OPG was initially identified as a key regulator in bone turnover (17-21). The expression of OPG at the RANK level translates into the inhibition of bone resorption by blocking osteoclastogenesis and reducing the activity of mature osteoclasts. At the osteoblastic level, OPG biosynthesis and secretion is stimulated by various cytokines, such as interleukins (ILs) (IL-1 and IL-6) and TNF- $\alpha$, while parathyroid hormone (PTH), 25-hydroxy vitamin D [25(OH) vitamin D] and prostaglandin E2 decrease the expression of OPG $(3,12,22-24)$. This inflammatory cytokine receptor is expressed in vivo by vascular smooth muscle cells, hepatic cells and osteoblasts, and its assessment is valuable for understanding the link between bone mineralization and vascular pathology (25-29). Clinical studies have suggested that OPG may also be a risk factor for progressive atherosclerotic cardiovascular disease $(9,16,27)$, mainly by mediating different processes in cells known to be implicated in the atherogenic process.

Another important discovery is that the pro-inflammatory environment that characterises MetS, leads to the secretion of OPG by endothelial tissue (2). Thus, endothelial cells express and release OPG under conditions of hyperglycaemia, hyperinsulinaemia, oxidative stress and various inflammatory stimuli $(1,2,13,28-30)$.

The aim of this study was to evaluate the value of OPG as a predictive marker for cardiovascular and metabolic risk in osteoporotic patients, in the constellate clinical millieu of MetS.

\section{Materials and methods}

The present study comprised 71 randomly selected women (48 post-menopausal and 23 pre-menopausal women) diagnosed with osteoporosis that were referred to the Endocrine Department of Elias Hospital (Bucharest, Romania).

The diagnosis of osteoporosis was made based on the WHO criteria, with a $\mathrm{T}$ score expressed in standard deviations (SD), either lumbar spine or neck, of $\leq-2.5$. Bone densitometry was evaluated using a GE Lunar DXA (dual X-ray absorptiometry) for lumbar (L1-L4) scan and femoral (neck) scans based on the DXA evaluation SDs. The results were expressed as bone mineral density (BMD) at lumbar and femoral neck sites, $\mathrm{T}$ score (SD resulting from the comparison to the young adult database) and $\mathrm{Z}$ score (SD resulting from the comparison to age- and sex-matched database). All these parameters were recorded for further analyses $(31,32)$.

Data collection consisted of clinical evaluation, physical exam and biochemical routine blood tests together with the assessment of bone turnover parameters required for the differential diagnosis of osteoporosis.

In this respect, we determined the levels of calcium in serum and urine, total alkaline phosphates (total ALP), PTH, $25(\mathrm{OH})$ vitamin $\mathrm{D}$, serum osteocalcin, OPG and beta crosslaps. Serum osteocalcin, OPG and $25(\mathrm{OH})$ vitamin D levels were assessed using immunological ELISA methods, PTH was analysed through a chemiluminometric method, while calcium and ALP levels were measured using spectrophotometric methods. Blood tests included the measurement of total serum cholesterol, HDL cholesterol, LDL cholesterol, triglyceride (TG) and blood glucose levels. The weight, height and waist circum- ference of the patients were also measured, as well as blood pressure, as previously described (1,4,33-38). All these methods used are described below:

ELISA. The serum levels osteocalcin, OPG 25(OH) vitamin D and beta crosslaps were assessed by ELISA on a Chemwell 2010 ELISA system (Awareness Technology Inc., Palm City, FL, USA) using commercially available kits provided by Immunodiagnostic Systems (The Boldons, UK).

N-MID ${ }^{\circledR}$ Osteocalcin ELISA is based upon the application of 2 highly specific monoclonal antibodies (Mabs) against human osteocalcin. An antibody recognizing the midregion (amino acids 20-29) was used as the capture antibody, and for detection a peroxidase conjugated antibody recognizing the $\mathrm{N}$-terminal region (amino acids 10-16) was used. In addition to intact osteocalcin (amino acid 1-49) the N-terminal-Mid fragment (amino acids 1-43) was also detected.

A sandwich-type ELISA assay was used for the direct determination of OPG in serum. In this assay, 2 highly specific antibodies against OPG were used. The binding antibody was attached to the wells of the microtiter plate, and the detection antibody was labelled with biotin. A sandwich-type complex was found consisting of the binding antibody on the plate, OPG and the biotinylated detection antibody.

A competitive ELISA technique with a selected monoclonal antibody recognizing $25(\mathrm{OH})$-vitamin D was employed. For a reliable determination of $25(\mathrm{OH})$-vitamin D, it is necessary to release it from the $25(\mathrm{OH})$-vitamin D-DBP-complex. Standards, controls and patient samples, which are assayed for $25(\mathrm{OH})$-vitamin $\mathrm{D}$, were incubated with the releasing reagent. The pre-incubated solutions were then transferred to the microplate coated with $25(\mathrm{OH})$-vitamin D, and an anti-25(OH)vitamin $\mathrm{D}$ antibody was added. Tetramethylbenzidine (TMB) was used as a peroxidase substrate and the intensity of the yellow color was inversely proportional to the concentration of 25(OH)-vitamin D.

The Serum CrossLaps ${ }^{\circledR}$ ELISA used, is based on 2 highly specific monoclonal antibodies against the amino acid sequence of EKAHD- $\beta$-GGR, where the aspartic acid residue (D) is $\beta$-isomerized. In order to obtain a specific signal in the Serum CrossLaps ${ }^{\circledR}$ ELISA, 2 chains of EKAHD- $\beta$-GGR must be cross linked.

Chemiluminometric methods. Serum PTH was assessed using the COBAS E 411 analyzer which is an automated, random-access, multichannel analyzer for immunological analysis. The development of ECL immunoassays is based on the use of a ruthenium chelate as the complex for the development of light. The chemiluminescent reactions that lead to the emission of light from the ruthenium complex are initiated electrically. This is achieved by applying a voltage to the immunological complexes (including the ruthenium complex) that are attached to Streptavidin-coated micro particles.

Spectrophotometric methods. ALP and total serum calcium were measured by spectrophotometric methods on a Jasco V 650 spectrometer. All reagents were supplied by Sigma-Aldrich.

Alkaline phosphatase in the sample catalyzes the hydrolysis of colorless p-nitrophenyl phosphate (p-NPP) to yield $\mathrm{p}$-nitrophenol and inorganic phosphate. At the $\mathrm{pH}$ of the assay 
Table I. Descriptive baseline parameters for all the subjects with measured osteoprotegerin levels.

\begin{tabular}{|c|c|c|c|c|c|c|c|c|c|c|c|}
\hline \multicolumn{4}{|c|}{ Age (years) } & \multicolumn{4}{|c|}{ Years since menopause } & \multicolumn{4}{|c|}{ BMI $\left(\mathrm{kg} / \mathrm{m}^{2}\right)$} \\
\hline Median & Min & Max & IQR & Median & Min & $\operatorname{Max}$ & $\mathrm{IQR}$ & Mean & Min & $\operatorname{Max}$ & SD \\
\hline 65.50 & 22.00 & 82.00 & 15.00 & 43.00 & 0.00 & 55.00 & 48.00 & 26.47 & 15.60 & 34.00 & 4.00 \\
\hline
\end{tabular}

$\mathrm{IQR}$, interquartile range; $\mathrm{SD}$, standard deviation.

(alkaline), the p-nitrophenol is in the yellow phenoxide form. The rate of absorbance increase at $404 \mathrm{~nm}$ is directly proportional to the alkaline phosphatase activity in the sample.

Total serum calcium was measured using the arsenazo-III dye that reacts with calcium in an acid solution to form a blue-purple complex. The color developed is measured at $660 \mathrm{~nm}$ and is proportional to the calcium concentration in the sample.

The age of the onset of menopause and the first menstruation were recorded. Fractures and exposure to risk factors for fracture were also recorded. All other associated diseases were noted and recorded.

The diagnosis of MetS was made based on the International Diabetes Federation (IDF) 2007 guidelines as follows: a waist circumference $>84 \mathrm{~cm}$ for women as a mandatory criteria along with a minimum of two other conditions: low HDL cholesterol ( $<40 \mathrm{mg} / \mathrm{dl}$ ), high TG levels ( $>150 \mathrm{mg} / \mathrm{dl})$, high blood pressure (>130 mmHg systolic, $>80 \mathrm{mmHg}$ diastolic) and high blood glucose (>100 mg/dl) levels $(3,12,27)$.

Ethics statement. Our research involved human participants and was approved by the Elias Hospital Ethics Committee, Bucharest, Romania. All clinical investigations were conducted according to the principles expressed in the Declaration of Helsinki, and all patients provided written and signed informed consent prior to enrollment.

Statistical analysis. Data analysis was performed using SPSS for Windows (version 20; IBM SPSS, Armonk, NY, USA). Variables were tested for normal distribution across study groups using the Shapiro-Wilk test and for comparison between mean and median values. Descriptive summary measures of the study variables were computed as appropriate: Mean and SD in normal distributed variables and median and interquartile range (IQR) in other variables. Pearson correlation coefficients were computed for bivariate correlation and significant correlations were discussed based on the P-value. A Student's t-test was used to compare variables across normally distributed variables. A non-parametric Mann Withney U test was used to compare continuous variables. The Canonical Discriminant Function coefficients were calculated in SPSS in order to assess the predictive value of different variables. A value of $\mathrm{P}<0.05$ was considered to indicate a statistically significant difference.

\section{Results}

The demographic parameters of all the subjects are illustrated in Table I. From the 71 patients, 48 were post-menopausal and 23 pre-menopausal. As an overall view, the period of time spent after menopause varied significantly and correlated with the age.
We found that some women underwent menopause at an earlier age. The mean BMI in our subjects was under the normal limits, with maximum values not exceeding the limit for severe obesity.

Routine blood test parameters in the study group revealed a wide range of blood glucose levels, suggesting that the study group also included subjects with diabetes mellitus and probably insulin-treated patients, the last situation explaining the very low glucose level in some cases. The lipid parameters also suggested a wide variety of dyslipidaemia in our subjects, as depicted in Table II.

Total serum calcium statistical parameters indicated that most of the values were aggregated near the normal values; however, patients with extremely low calcium levels were also found among our patients. A low blood calcium level is not a common feature in osteoporosis, but is rather a similar situation as low glucose levels, with patients being admitted to the endocrine department following an acute episode of hypocalcaemia.

Hypercalcaemia is more frequently observed in patients diagnosed with osteoporosis, primary hyperparathyroidism being one of the most important secondary causes of osteoporosis $(20,39)$. Consequently, the measurement of calcium and PTH is a mandatory step in the process for the differential diagnosis of osteoporosis. Failing to identify the secondary cause in osteoporosis will decrease the treatment efficacy and will allow the untreated condition to evolve and lead to complications.

Among other markers, 25(OH) vitamin D may be considered by some specialised departments as a routine test for the differential diagnosis of osteoporosis $(38,40,41)$. In our patients, we found very low levels of $25(\mathrm{OH})$ vitamin $\mathrm{D}$, somehow confirming other reports; the median value was $<30 \mathrm{ng} / \mathrm{ml}$, which indicated that most of our subjects had inadequate serum $25(\mathrm{OH})$ vitamin D levels (Table II). Osteocalcin and crosslaps, as biochemical markers of bone turnover, had a specific value in differentiating specific situations or monitoring treatment, the absolute baseline value being not very specific.

Correlation coefficients and the statistical significance between calcium, the lipidic and glucidic profiles and bone turnover parameters were computed and are presented in Table III.

Serum total calcium correlated with the time spent in the post-menopausal period in these patients, justified probably by the well-known increase in hyperparathyroidism in the forth and sixth decades of life in women. Calcaemia also significantly correlated with crosslaps, a marker of bone turnover; this indicates that even in the case of small variations, serum total calcium correlates with increased bone turnover.

On the other hand, serum total calcium (plasmatic $\mathrm{Ca}^{2+}$ ) was also found to inversely correlate with the urinary calcium excretion; this association is normal mostly in high resorbtive 
Table II. Descriptive statistics for lipid and glucose blood parameters.

\begin{tabular}{lcccc}
\hline Parameter & Median & Minimum & Maximum & Interquartile range \\
\hline Blood glucose (mg/dl) & 89 & 54 & 255 & 15 \\
Cholesterol total (mg/dl) & 211.22 & 205.31 & 383.58 & 57.8 \\
HDL cholesterol (mg/dl) & 57.13 & 15.74 & 125.35 & 68.51 \\
LDL cholesterol (mg/dl) & 126.34 & 119.62 & 145.74 & 65.02 \\
TG (mg/dl) & 240.76 & 151.81 & 524.96 & 97.83 \\
Serum calcium (mg/dl) & 9.6 & 3 & 11.6 & 0.7 \\
Urine calcium (mg/24 h) & 147.19 & 24.7 & 560.74 & 152.39 \\
Total ALP (UI/l) & 88.5 & 21 & 184 & 97 \\
PTH (pg/ml) & 68.50 & 57.3 & 18.6 & 45.49 \\
25(OH) vitamin D (ng/ml) & 9.7 & 6.6 & 13.1 & 4.5 \\
Osteocalcin (ng/ml) & 10.40 & 2 & 1.704 & 9.21 \\
Crosslaps (ng/ml) & 0.185 & 0.015 & 7.62 & 0.35 \\
Osteoprotegerin (pmol/l) & 5.26 & 2.9 & 3.6 \\
\hline
\end{tabular}

TG, triglycerides; ALP, alkaline phosphate; PTH, parathyroid hormone; 25(OH) vitamin D, 25-hydroxy vitamin D.

Table III. Pearson correlation's coefficients between calcium, specific bone parameters and metabolic biomarkers.

\begin{tabular}{|c|c|c|c|c|c|c|c|c|}
\hline Parameter & $\begin{array}{c}\text { Age } \\
\text { (years) }\end{array}$ & $\begin{array}{c}\text { BMI } \\
\left(\mathrm{kg} / \mathrm{m}^{2}\right)\end{array}$ & $\begin{array}{l}\text { Years since } \\
\text { menopause }\end{array}$ & $\begin{array}{l}\text { Blood } \\
\text { glucose } \\
(\mathrm{mg} / \mathrm{dl})\end{array}$ & $\begin{array}{c}\text { Total } \\
\text { cholesterol } \\
(\mathrm{mg} / \mathrm{dl})\end{array}$ & $\begin{array}{c}\text { HDL } \\
\text { cholesterol } \\
(\mathrm{mg} / \mathrm{dl})\end{array}$ & $\begin{array}{c}\text { LDL } \\
\text { cholesterol } \\
(\mathrm{mg} / \mathrm{dl})\end{array}$ & $\begin{array}{c}\mathrm{TG} \\
(\mathrm{mg} / \mathrm{dl})\end{array}$ \\
\hline Serum total calcium (mg/dl) & 0.151 & -0.176 & $-0.546^{\mathrm{a}}$ & -0.200 & -0.169 & 0.395 & -0.283 & -0.233 \\
\hline Calcium urine excretion (mg/24 h) & -0.098 & 0.268 & 0.373 & 0.080 & -0.544 & -0.425 & -0.181 & 0.008 \\
\hline Total ALP (UI/l) & 0.310 & 0.090 & 0.103 & 0.211 & 0.134 & -0.103 & 0.090 & 0.143 \\
\hline PTH (pg/ml) & 0.065 & 0.128 & 0.090 & $0.491^{\mathrm{b}}$ & 0.127 & 0.225 & 0.030 & $0.268^{\mathrm{a}}$ \\
\hline $25(\mathrm{OH})$ vitamin $\mathrm{D}(\mathrm{ng} / \mathrm{ml})$ & $-0.358^{\mathrm{b}}$ & -0.100 & 0.261 & -0.152 & -0.170 & -0.101 & -0.128 & -0.267 \\
\hline Osteocalcin (ng/ml) & -0.194 & -0.116 & 0.206 & -0.011 & 0.035 & $0.344^{\mathrm{a}}$ & -0.035 & -0.136 \\
\hline Crosslaps (ng/ml) & -0.598 & 0.458 & 0.212 & -0.101 & 0.040 & $0.830^{\mathrm{b}}$ & -0.586 & -0.008 \\
\hline Osteoprotegerin (pmol/l) & 0.101 & 0.078 & -0.079 & 0.245 & 0.246 & $0.333^{\mathrm{a}}$ & 0.264 & 0.023 \\
\hline
\end{tabular}

${ }^{a}$ Correlation is significant at the 0.05 level (2-tailed). ${ }^{\mathrm{b}}$ Correlation is significant at the 0.01 level (2-tailed). ALP, alkaline phosphate; PTH, parathyroid hormone; $25(\mathrm{OH})$ vitamin $\mathrm{D}, 25$-hydroxy vitamin $\mathrm{D}$; TG, triglycerides.

Table IV. Pearson correlation's coefficients between calcium and bone parameters.

\begin{tabular}{|c|c|c|c|c|c|c|c|}
\hline Parameter & $\begin{array}{c}\text { Serum total } \\
\text { calcium }(\mathrm{mg} / \mathrm{dl})\end{array}$ & $\begin{array}{l}\text { Calcium urine } \\
\text { excretion } \\
(\mathrm{mg} / 24 \mathrm{~h})\end{array}$ & $\begin{array}{l}\text { Total ALP } \\
\text { (UI/l) }\end{array}$ & $\begin{array}{c}\text { PTH } \\
(\mathrm{pg} / \mathrm{ml})\end{array}$ & $\begin{array}{c}25(\mathrm{OH}) \\
\text { vitamin D } \\
(\mathrm{ng} / \mathrm{ml})\end{array}$ & $\begin{array}{l}\text { Osteocalcin } \\
(\mathrm{ng} / \mathrm{ml})\end{array}$ & $\begin{array}{c}\text { Crosslaps } \\
(\mathrm{ng} / \mathrm{ml})\end{array}$ \\
\hline Serum total calcium $(\mathrm{mg} / \mathrm{dl})$ & 1 & $-0.610^{\mathrm{a}}$ & 0.054 & 0.245 & -0.293 & 0.074 & $1.000^{\mathrm{b}}$ \\
\hline $\begin{array}{l}\text { Calcium urine } \\
\text { excretion }(\mathrm{mg} / 24 \mathrm{~h})\end{array}$ & $-0.610^{\mathrm{a}}$ & 1 & 0.41 & 0.284 & 0.376 & -0.351 & -0.78 \\
\hline Total ALP (UI/l) & 0.050 & -0.509 & 1 & $0.782^{\mathrm{a}}$ & -0.156 & -0.054 & 0.654 \\
\hline PTH (pg/ml) & 0.245 & 0.284 & 0.45 & 1 & -0.155 & 0.172 & -0.222 \\
\hline $25(\mathrm{OH})$ vitamin $\mathrm{D}(\mathrm{ng} / \mathrm{ml})$ & -0.293 & 0.376 & -0.011 & -0.155 & 1 & 0.023 & 0.366 \\
\hline Osteocalcin (ng/ml) & 0.074 & -0.351 & -0.034 & 0.172 & 0.023 & 1 & -0.103 \\
\hline Crosslaps (ng/ml) & $1.000^{\mathrm{b}}$ & -0.213 & 0.654 & -0.222 & 0.366 & -0.103 & 1 \\
\hline Osteoprotegerin (pmol/l) & 0.300 & -0.460 & $0.78^{\mathrm{a}}$ & $0.332^{\mathrm{b}}$ & 0.006 & 0.068 & -0.413 \\
\hline
\end{tabular}

${ }^{\mathrm{a} C}$ Correlation is significant at the 0.05 level (2-tailed). ${ }^{\mathrm{b}}$ Correlation is significant at the 0.01 level (2-tailed). ALP, alkaline phosphate; PTH, parathyroid hormone; $25(\mathrm{OH})$ vitamin $\mathrm{D}, 25$-hydroxy vitamin $\mathrm{D}$. 
Table V. Pearson correlation's coefficients between calcium, bone and densitometric parameters.

\begin{tabular}{|c|c|c|c|c|c|c|}
\hline Parameter & $\begin{array}{c}\text { Lumbar } \\
\text { BMD } \\
\left(\mathrm{g} / \mathrm{cm}^{2}\right)\end{array}$ & $\begin{array}{c}\text { Lumbar } \\
\text { T score } \\
\text { (SD) }\end{array}$ & $\begin{array}{l}\text { Lumbar } \\
\text { Z score } \\
\text { (SD) }\end{array}$ & $\begin{array}{c}\text { Femoral } \\
\text { BMD } \\
\left(\mathrm{g} / \mathrm{cm}^{2}\right)\end{array}$ & $\begin{array}{c}\text { Femoral } \\
\text { T score } \\
(\mathrm{SD})\end{array}$ & $\begin{array}{c}\text { Femoral } \\
\text { Z score } \\
\text { (SD) }\end{array}$ \\
\hline Serum total calcium $(\mathrm{mg} / \mathrm{dl})$ & -0.213 & 0.167 & -0.249 & -0.157 & 0.266 & 0.215 \\
\hline Calcium urine excretion (mg/24 h) & 0.034 & -0.280 & 0.097 & -0.322 & -0.207 & -0.374 \\
\hline Total ALP(UI/l) & 0.143 & -0.290 & -0.011 & -0.055 & -0.311 & -0.090 \\
\hline PTH (pg/ml) & -0.041 & -0.140 & -0.039 & -0.098 & -0.091 & -0.084 \\
\hline $25(\mathrm{OH})$ vitamin $\mathrm{D}(\mathrm{ng} / \mathrm{ml})$ & 0.163 & -0.267 & -0.162 & 0.060 & -0.091 & -0.244 \\
\hline Osteocalcin (ng/ml) & 0.000 & -0.007 & -0.037 & 0.056 & 0.031 & 0.010 \\
\hline Crosslaps (ng/ml) & -0.002 & 0.646 & -0.072 & 0.749 & 0.415 & 0.106 \\
\hline Osteoprotegerin ( $\mathrm{pmol} / \mathrm{l})$ & -0.025 & -0.032 & -0.100 & -0.001 & -0.079 & -0.073 \\
\hline
\end{tabular}

ALP, alkaline phosphate; PTH, parathyroid hormone; SD, standard deviation; 25(OH) vitamin D, 25-hydroxy vitamin D.

Table VI. Comparison between study subgroups according to the MetS presence criteria: Clinical, bone and metabolic parameters.

\begin{tabular}{|c|c|c|}
\hline Parameter & Control group (no MetS) & Study group (MetS present) \\
\hline Age $(\text { years })^{\mathrm{a}}$ & $61(19)$ & $70(17.5)$ \\
\hline BMI $\left(\mathrm{kg} / \mathrm{m}^{2}\right)^{\mathrm{b}}$ & $24.5(4.7)$ & $26.3(3.7)$ \\
\hline Years since menopause ${ }^{a}$ & $40(45)$ & $41(48)$ \\
\hline Blood glucose $(\mathrm{mg} / \mathrm{dl})^{\mathrm{a}}$ & $87(12)$ & $107(17)$ \\
\hline Total cholesterol $(\mathrm{mg} / \mathrm{dl})^{\mathrm{b}}$ & $200(53.8)$ & $231.8(42.89)$ \\
\hline HDL cholesterol $(\mathrm{mg} / \mathrm{dl})^{\mathrm{a}}$ & $56(18)$ & $58(17)$ \\
\hline LDL cholesterol (mg/dl) $)^{b}$ & $119(43.3)$ & $138(43.1)$ \\
\hline Triglycerides $(\mathrm{mg} / \mathrm{dl})^{\mathrm{b}}$ & $94.4(35.1)$ & $146.1(52.5)$ \\
\hline Serum total $\mathrm{Ca}(\mathrm{mg} / \mathrm{dl})^{\mathrm{b}}$ & $9.3(0.5)$ & $10(0.8)$ \\
\hline $24 \mathrm{~h}$ urine calcium $(\mathrm{mg} / 24 \mathrm{~h})^{\mathrm{a}}$ & $158(151)$ & $118(168)$ \\
\hline Total ALP (UI/l) $)^{\mathrm{a}}$ & $87(90)$ & $134(109)$ \\
\hline PTH $(\mathrm{pg} / \mathrm{ml})^{\mathrm{a}}$ & $77.2(13.3)$ & $80.6(16.9)$ \\
\hline $25(\mathrm{OH})$ vitamin $\mathrm{D}(\mathrm{ng} / \mathrm{ml})^{\mathrm{a}}$ & $30(39)$ & $17.4(11.1)$ \\
\hline Osteocalcin $(\mathrm{ng} / \mathrm{ml})^{\mathrm{a}}$ & $10.4(12.4)$ & $10.1(10.1)$ \\
\hline Crosslaps $(\mathrm{ng} / \mathrm{ml})^{\mathrm{a}}$ & $0.448(0.137)$ & $0.132(0.389)$ \\
\hline Osteoprotegerin baseline $(\mathrm{pmol} / \mathrm{l})^{\mathrm{b}}$ & $5.15(0.54)$ & $5.6(0.68)$ \\
\hline
\end{tabular}

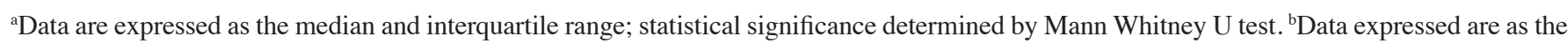
mean and standard deviation; statistical significance determined by Student's t-test. MetS, metabolic syndrome; ALP, alkaline phosphate; PTH, parathyroid hormone; 25(OH) vitamin D, 25-hydroxy vitamin D.

states (20). As previously described (39), calcium excretion into urine is dependent on bone resorption and calcium intake; consequently it is higher in increased bone resorption states. Since all the women in our study group had osteoporosis and most of them had low vitamin D levels, calciuria exhibited an inverse correlation with blood calcium levels due to the PTH effect on the kidney function. No significant correlations were found with bone densitometry parameters (Table V).

Serum total ALP levels (as presented in Table IV) exhibited a significant correlation with serum PTH levels, illustrating the direct effect of PTH on the renal handling of calcium: PTH decreases the renal loss of calcium into urine. The direct correlation with OPG may be explained by the link with bone resorption: both parameters, total ALP and OPG may be increased in relation to the increased osteoclast activity in the bone.

The correlations of the PTH serum levels with age (Table III) or the serum $25(\mathrm{OH})$ vitamin D levels (Table IV) were not significant probably due to the low number of cases. Nevertheless, PTH did correlate with the blood glucose and serum TG levels (Table III). These correlations sustain the hypothesis of metabolic and cardiovascular risk associated even with normocalcemic primary hyperparathyroidism.

The serum 25(OH) vitamin D levels were found to negatively correlate with age (Table III) in our study group. Increased age is a well-known risk factor for low $25(\mathrm{OH})$ vitamin D levels, which was confirmed in our data. Several factors found in 

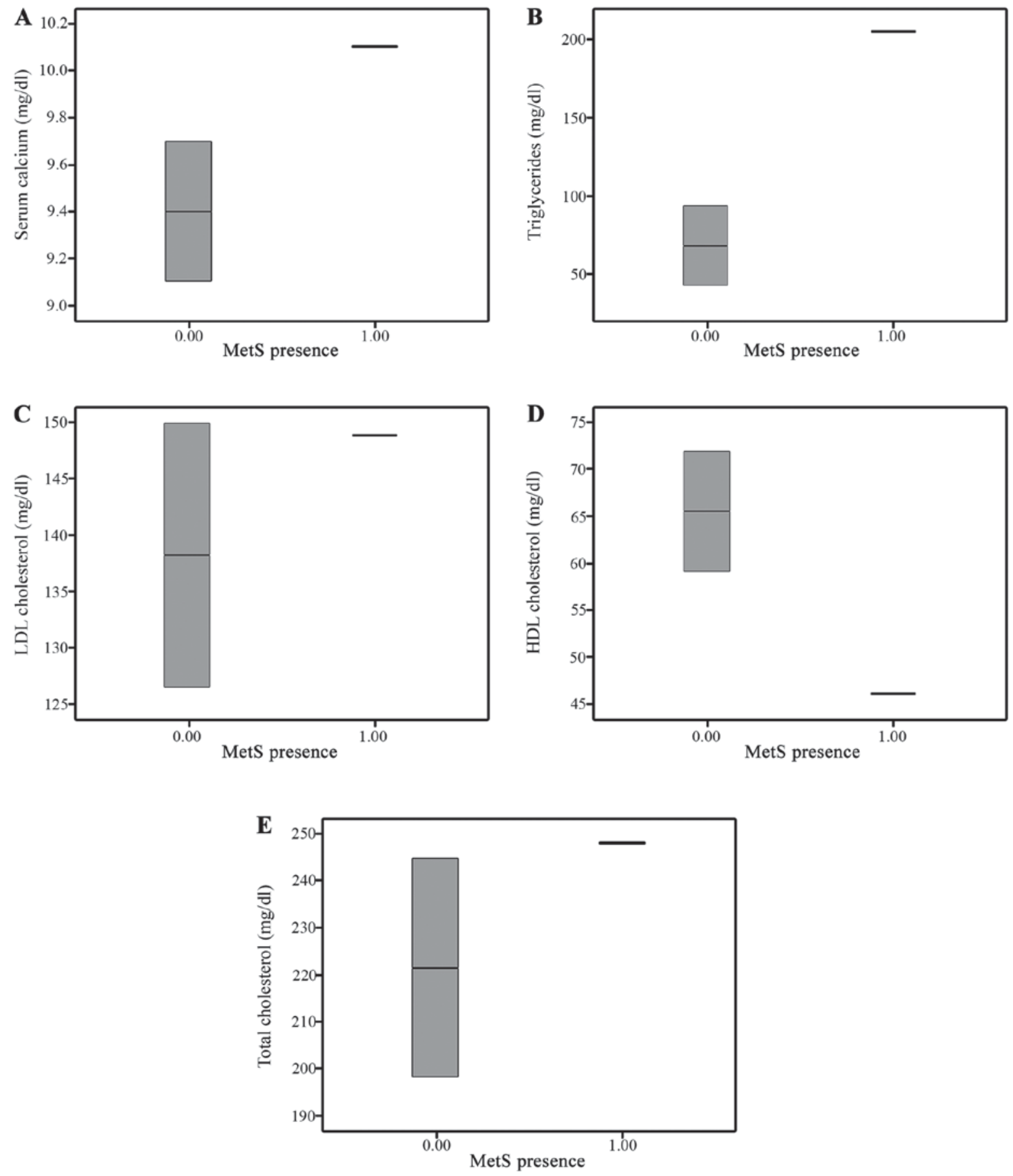

Figure 1. Correlations of (A) total serum calcium (mg/dl), (B) triglycerides (mg/dl), (C) LDL cholesterol (mg/dl), (D) HDL cholesterol (mg/dl), (E) total cholesterol $(\mathrm{mg} / \mathrm{dl})$ with the occurrence of metabolic syndrome. MetS, metabolic syndrome.

Table VII. Standardized Canonical Discriminant Function Coefficients and significance in predicting Mets occurance.

\begin{tabular}{lcr}
\hline Parameter & Coefficient & P-value \\
\hline PTH $(\mathrm{pg} / \mathrm{ml})$ & 0.144 & 0.193 \\
OPG $(\mathrm{pmol} / \mathrm{l})$ & 0.673 & 0.022 \\
$25(\mathrm{OH})$ Vit D $(\mathrm{ng} / \mathrm{ml})$ & -0.765 & 0.009 \\
\hline
\end{tabular}

PTH, parathyroid hormone; OPG, osteoprotegerin; 25(OH) Vit D, 25-hydroxy vitamin D [25(OH) vitamin D. elderly individuals may be the cause of this aspect: low sun exposure due to invalidity, skin alterations with age and the decreased activation of vitamin $\mathrm{D}$ in the kidneys. The inverse correlation between PTH and 25(OH) vitamin D levels was not significant; an explanation for this may be the lower case number or the lower prevalence of vitamin D deficiency in this group which alleviates it.

Serum osteocalcin levels were found to directly correlate with HDL cholesterol in the OPG group (Table III), a correlation explained by the utility of osteocalcin in the evaluation of cardiovascular risk, an intensively explored aspect in the 

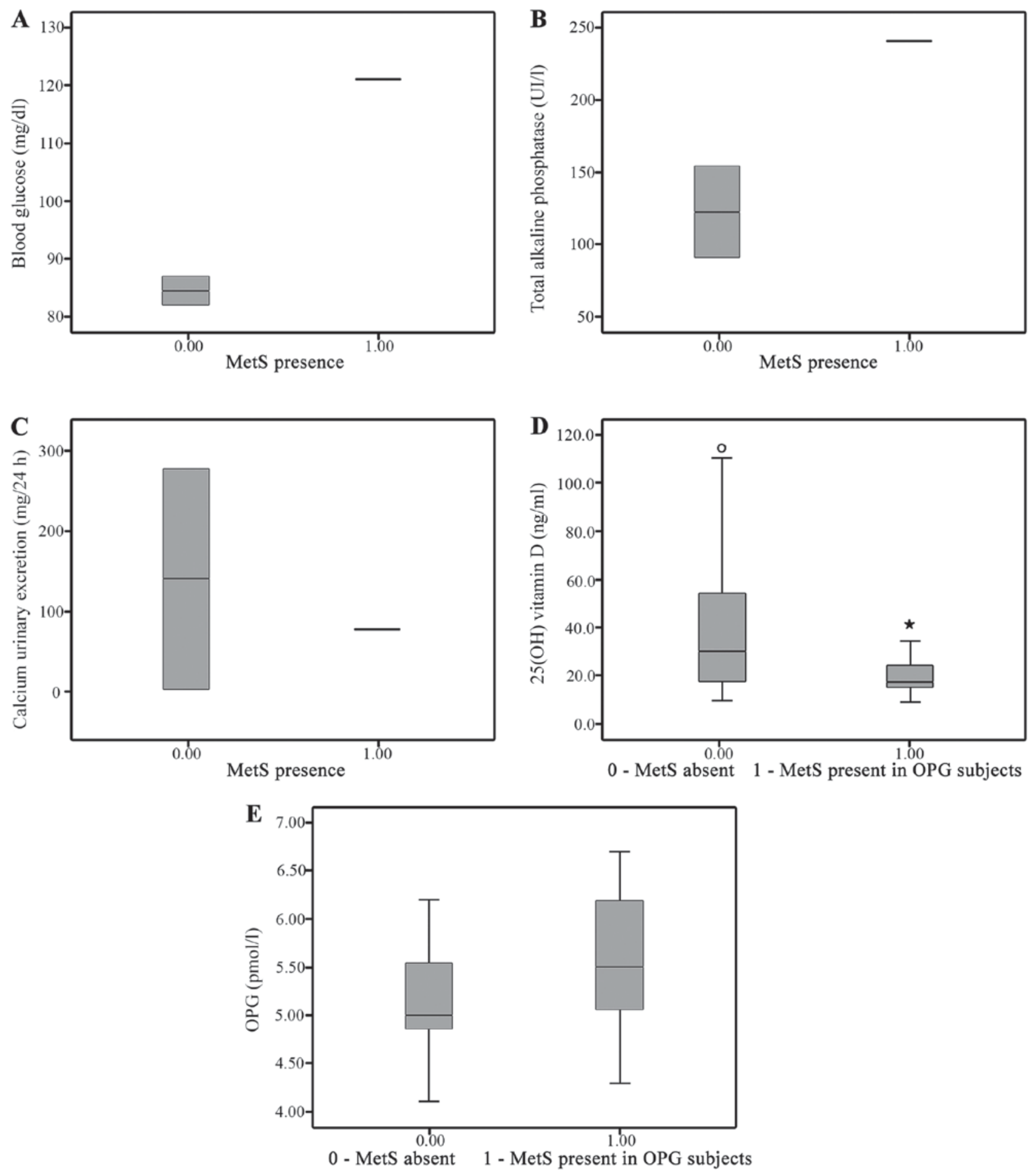

Figure 2. Correlations of (A) blood glucose (mg/dl), (B) total alkaline phosphatase (UI/l), (C) calcium urinary excretion (mg/24 h), (D) 25(OH) vitamin D (ng/ $\mathrm{ml}$ ), (E) OPG (pmol/l) with the occurrence of metabolic syndrome. OPG, osteoprotegerin; MetS, metabolic syndrome; 25(OH) vitamin D, 25-hydroxy vitamin D.

past years. Osteocalcin did not correlate with blood calcium levels, PTH levels and serum crosslaps (Table IV). The utility and significance of osteocalcin levels measured in serum as a reliable marker of bone turnover, regarding both resorption and formation, are based on larger group analysis $(34,39)$. This aspect led to complications in the individual patient value of osteocalcin measurements. This biomarker is not yet clinically validated as a diagnostic tool for bone turnover, and therefore it is mainly used for research purposes.
The OPG serum levels were found to directly and significantly correlate with HDL cholesterol, total ALP and serum PTH levels (Tables III and IV). These correlations sustain the protective role of the OPG for cardiovascular diseases and, in the same time, the link to the bone metabolism.

No significant correlation was found between biochemical calcium levels, bone markers and densitometric parameters in our population (as depicted in Table V). This may be explained by the independent value of these markers in the fracture risk 
evaluation; it is well known that the correlation between densitometric and biochemical aspects in osteoporosis is not linear and is somehow divergent $(31,32,36)$.

Correlation between serum OPG levels and MetS. Women with measured OPG serum levels were also segregated into two subgroups considering the presence of Mets: a control group without Mets and a study group with Mets (as presented in Table VI).

There were some significant differences across these two groups as regards age and blood glucose, total and HDL cholesterol and serum TG levels (Fig. 1). All these differences are completely explained by the selection criteria: the diagnosis of MetS is based on decreased HDL cholesterol levels, increased blood glucose levels and increased TG levels. On the other hand, the prevalence of MetS is increasing with age; consequently, increased age in the study group was a normal finding. Among the calcium and bone biochemical markers, the $25(\mathrm{OH})$ vitamin D and OPG serum levels were significantly different across the study groups (Fig. 2).

\section{Discussion}

The serum level of $25(\mathrm{OH})$ vitamin D (Fig. 1) was significantly lower in the Mets group, in accordance with the reports of increased cardiovascular risk associated with vitamin D deficiency $(38,40)$.

Vitamin D has been shown in several studies to be implicated in the maintenance of the good function of the immune system, vitamin D deficiency has been associated with neoplasia and diabetes, as well as atherosclerosis and insulin resistance $(22,42,43)$.

We found a significant difference in terms of serum $25(\mathrm{OH})$ vitamin $\mathrm{D}$ levels between the two groups, differences suggesting that vitamin D deficiency may be a risk factor for the development of MetS and its related complications, such as diabetes and atherosclerosis.

The OPG levels were higher in the Mets group (Fig. 2). It has been suggested that increased levels of OPG in patients with cardiovascular risk are due to the protective effect of OPG; however, the underlying mechanisms are still under debate $(2,4,11-16)$.

Correlations between OPG and 25(OH) vitamin D levels in the presence of MetS as an indicator of cardiovascular risk were further analysed in order to exclude other co-founding factors. Due to the correlations between OPG and total ALP levels, as well as PTH and HDL cholesterol, suggesting that the differences in OPG levels between the Mets groups may be mediated by one of these parameters, a discriminant analysis (SPSS discriminant function analysis) was performed. The results revealed a significant predictive value for OPG and $25(\mathrm{OH})$ vitamin $\mathrm{D}$ for Mets $(\mathrm{P}<0.05)$. PTH was not significantly predictive $(\mathrm{P}>0.05)$ (Table VII). Cholesterol parameters were not included in this analysis, as the significant difference found between the Mets subgroups were due to the selection criteria (Mets definition) (13-15).

The levels of serum total calcium, calcium excretion, serum PTH and bone resorption markers correlated with each other in our patients with osteoporosis, sustaining their relevance for bone turnover evaluation in osteoporosis.

Significant correlations between classical biochemical bone and calcium parameters, such as osteocalcin and PTH with lipid and glucose metabolism, were found in our patients, sustaining the crosstalk between calcium, bone parameters and cardiovascular risk.

The OPG serum level was proven to have a significant and independent predictive value for MetS as a cardiovascular risk factor in osteoporotic patients. The OPG serum levels were increased in patients with MetS as a protective response against atherosclerotic lesions.

The serum levels of $25(\mathrm{OH})$ vitamin D had significant and independent predictive values for the cardiovascular and metabolic risk in our subjects sustaining the wide role of the vitamin $\mathrm{D}$ outside the bone metabolism.

\section{References}

1. Suliburska J, Bogdanski P, Gajewska E, Kalmus G, Sobieska M and Samborski W: The association of insulin resistance with serum osteoprotegerin in obese adolescents. J Physiol Biochem 69: 847-853, 2013.

2. Villacampa de Ciriza Perez C: Osteoprotegerin: A promising biomarker in the metabolic syndrome - New perspectives. Biochem Anal Biochem 5: 1-3, 2016.

3. Fuentes E, Fuentes F, Vilahur G, Badimon L and Palomo I: Mechanisms of chronic state of inflammation as mediators that link obese adipose tissue and metabolic syndrome. Mediators Inflamm 2013: 136584, 2013.

4. Monseu M, Dubois S, Boursier J, Aubé C, Gagnadoux F, Lefthériotis G and Ducluzeau PH: Osteoprotegerin levels are associated with liver fat and liver markers in dysmetabolic adults. Diabetes Metab 42: 364-367, 2016.

5. Docea AO, Vassilopoulou L, Fragou D, Arsene AL, Fenga C, Kovatsi L, Petrakis D, Rakitskii VN, Nosyrevh AE, Izotovh BN, et al: CYP polymorphisms and pathological conditions related to chronic exposure to organochlorine pesticides. Toxicol Rep 4: 335-341, 2017.

6. Drăgoi CM, Nicolae AC, Grigore C, Dinu-Pîrvu CE and Arsene AL: Characteristics of glucose homeostasis and lipidic profile in a hamster metabolic syndrome model, after the co-administration of melatonin and irbesartan in a multiparticulate pharmaceutical formulation. In: The Second International Conference on Interdisciplinary Management of Diabetes Mellitus and its Complications, INTERDIAB 2016, 3-5 March, Diabetes Mellitus as Cardiovascular Disease, Ed. Niculescu, Bucharest, pp221-229, 2016

7. Hernández AF, Parrón T, Tsatsakis AM, Requena M, Alarcón R and López-Guarnido O: Toxic effects of pesticide mixtures at a molecular level: Their relevance to human health. Toxicology 307: 136-145, 2013.

8. Mrema EJ, Rubino FM, Brambilla G, Moretto A, Tsatsakis AM and Colosio C: Persistent organochlorinated pesticides and mechanisms of their toxicity. Toxicology 307: 74-88, 2013.

9. Aguilera AA, Diaz GH, Barcelata ML, Guerrero OA and Ros RM: Effects of fish oil on hypertension, plasma lipids, and tumor necrosis factor-alpha in rats with sucrose-induced metabolic syndrome. J Nutr Biochem 15: 350-357, 2004.

10. Klöting N, Blüher M and Klöting I: The polygenetically inherited metabolic syndrome of WOKW rats is associated with insulin resistance and altered gene expression in adipose tissue. Diabetes Metab Res Rev 22: 146-154, 2006.

11. Augoulea A, Vrachnis N, Lambrinoudaki I, Dafopoulos K, Iliodromiti Z, Daniilidis A, Varras M, Alexandrou A, Deligeoroglou $E$ and Creatsas G: Osteoprotegerin as a marker of atherosclerosis in diabetic patients. Int J Endocrinol 2013: 182060, 2013.

12. Bernardi S, Fabris B, Thomas M, Toffoli B, Tikellis C, Candido R, Catena C, Mulatero P, Barbone F, Radillo O, et al: Osteoprotegerin increases in metabolic syndrome and promotes adipose tissue proinflammatory changes. Mol Cell Endocrinol 394: 13-20, 2014.

13. Bjerre M: Osteoprotegerin (OPG) as a biomarker for diabetic cardiovascular complications. Springerplus 2: 658, 2013.

14. Gordin D, Soro-Paavonen A, Thomas MC, Harjutsalo V, Saraheimo M, Bjerre M, Forsblom C, Flyvbjerg A and Groop PH; FinnDiane Study Group: Osteoprotegerin is an independent predictor of vascular events in Finnish adults with type 1 diabetes. Diabetes Care 36: 1827-1833, 2013. 
15. Guo C, Hu F, Zhang S, Wang Y and Liu H: Association between osteoprotegerin gene polymorphisms and cardiovascular disease in type 2 diabetic patients. Genet Mol Biol 36: 177-182, 2013.

16. Montagnana M,Lippi G, Danese E and Guidi GC: The role of osteoprotegerin in cardiovascular disease. Ann Med 45: 254-264, 2013.

17. Baud'huin M, Duplomb L, Teletchea S, Lamoureux F, Ruiz-Velasco C, Maillasson M, Redini F, Heymann MF and Heymann D: Osteoprotegerin: Multiple partners for multiple functions. Cytokine Growth Factor Rev 24: 401-409, 2013

18. Chen Z, Xue J, Shen T, Mu S and Fu Q: Curcumin alleviates glucocorticoid-induced osteoporosis through the regulation of the Wnt signaling pathway. Int J Mol Med 37: 329-338, 2016.

19. Ndip A, Wilkinson FL, Jude EB, Boulton AJ and Alexander MY: RANKL-OPG and RAGE modulation in vascular calcification and diabetes: Novel targets for therapy. Diabetologia 57: 2251-2260, 2014.

20. Xiong J, Piemontese M, Thostenson JD, Weinstein RS, Manolagas SC and O'Brien CA: Osteocyte-derived RANKL is a critical mediator of the increased bone resorption caused by dietary calcium deficiency. Bone 66: 146-154, 2014.

21. Zhang Y, Shao J, Wang Z, Yang T, Liu S, Liu Y, Fan X and Ye W: Aqueous extract of pomegranate seed attenuates glucocorticoid-induced bone loss and hypercalciuria in mice: A comparative study with alendronate. Int J Mol Med 38: 491-498, 2016

22. Bischoff-Ferrari HA and Staehelin HB: Importance of vitamin D and calcium at older age. Int J Vitam Nutr Res 78: 286-292, 2008

23. O'Brien EA, Williams JH and Marshall MJ: Osteoprotegerin is produced when prostaglandin synthesis is inhibited causing osteoclasts to detach from the surface of mouse parietal bone and attach to the endocranial membrane. Bone 28:208-214, 2001

24. Nan R, Grigorie D, Cursaru A, Șucaliuc A, Drăguț R, Rusu E, Mușat M and Radulian G: Bisphosphonates - A good choice for women with type 2 diabetes and postmenopausal osteoporosis? Farmacia 64: 257-261, 2016.

25. Cima LN and Fica S: The use of anabolic therapy in patients with betathalassemia major-induced osteoporosis - review of the literature. Farmacia 65: 167-172, 2017.

26. Lee CJ, Wang JH, Chen ML, Yang CF, Chen YC and Hsu BG: Serum osteoprotegerin is associated with arterial stiffness assessed according to the cardio-ankle vascular index in hypertensive patients. J Atheroscler Thromb 22: 304-312, 2015.

27. Pérez de Ciriza C, Moreno M, Restituto P, Bastarrika G, Simón I, Colina I and Varo N: Circulating osteoprotegerin is increased in the metabolic syndrome and associates with subclinical atherosclerosis and coronary arterial calcification. Clin Biochem 47: 272-278, 2014

28. Yu G, Ji X, Jin J and Bu S: Association of serum and vitreous concentrations of osteoprotegerin with diabetic retinopathy. Ann Clin Biochem 52: 232-236, 2015.

29. Zhu M, Fang X, Zhou S, Li W and Guan S: Indirect co culture of vascular smooth muscle cells with bone marrow mesenchymal stem cells inhibits vascular calcification and downregulates the Wnt signaling pathways. Mol Med Rep 13: 5141-5148, 2016.
30. Wang ST, Xu JM, Wang M, Chen FL and Ding G: Increased plasma osteoprotegerin concentrations in type 1 diabetes with albuminuria. Clin Nephrol 79: 192-198, 2013.

31. Borman P, Babaoğlu S, Gur G, Bingol S and Bodur H: Bone mineral density and bone turnover in patients with psoriatic arthritis. Clin Rheumatol 27: 443-447, 2008.

32. Kanis JA, McCloskey EV, Johansson H, Cooper C, Rizzoli R and Reginster JY; Scientific Advisory Board of the European Society for Clinical and Economic Aspects of Osteoporosis and Osteoarthritis (ESCEO) and the Committee of Scientific Advisors of the International Osteoporosis Foundation (IOF): European guidance for the diagnosis and management of osteoporosis in postmenopausal women. Osteoporos Int 24: 23-57, 2013.

33. Christgau S, Rosenquist C, Alexandersen P, Bjarnason NH, Ravn P, Fledelius C, Herling C, Qvist P and Christiansen C: Clinical evaluation of the Serum CrossLaps One Step ELISA, a new assay measuring the serum concentration of bone-derived degradation products of type I collagen C-telopeptides. Clin Chem 44: 2290-2300, 1998

34. Grădinaru D, Mitrea N, Margină D, Arsene AL, Gruia V, Drăgoi C, Nicolae A, Borşa C and Gherasim P: Evaluation of serum osteocalcin in eldery patients with type-2 diabetes mellitus. Farmacia 57: 331-338, 2009.

35. Hamann KL and Lane NE: Parathyroid hormone update. Rheum Dis Clin North Am 32: 703-719, 2006.

36. Henriksen K, Karsdal MA and Martin TJ: Osteoclast-derived coupling factors in bone remodeling. Calcif Tissue Int 94: 88-97, 2014.

37. Starup-Linde J, Eriksen SA, Lykkeboe S, Handberg A and Vestergaard P: Biochemical markers of bone turnover in diabetes patients - a meta-analysis, and a methodological study on the effects of glucose on bone markers. Osteoporos Int 25: 1697-1708, 2014.

38. Kamineni V, Latha AP and Ramathulasi K: Association between serum 25-hydroxyvitamin D levels and bone mineral density in normal postmenopausal women. J Midlife Health 7: 163-168, 2016.

39. Wael Rasheed N, Barbu CG, Florea S, Branceanu G, Fica S, Mitrea N, Dragoi CM, Nicolae AC and Arsene AL: Biochemical markers of calcium and bone metabolism in the monitoring of osteoporosis treatment. Farmacia 62: 728-736, 2014.

40. Ohta H, Uemura Y, Nakamura T, Fukunaga M, Ohashi Y, Hosoi T, Mori S, Sugimoto T, Itoi E, Orimo $\mathrm{H}$, et al; Adequate Treatment of Osteoporosis (A-TOP) Research Group: Serum 25-hydroxyvitamin D level as an independent determinant of quality of life in osteoporosis with a high risk for fracture. Clin Ther 36: 225-235, 2014

41. Zugravu CA, Soptica F, Tarcea M and Cucu A: Pertinence of vitamin $D$ supplementation in the adult Romanian population. Farmacia 64: 467-472, 2016.

42. Heaney RP: The vitamin D requirement in health and disease. J Steroid Biochem Mol Biol 97: 13-19, 2005.

43. Holick MF: Vitamin D: A millenium perspective. J Cell Biochem 88: 296-307, 2003. 